\title{
Acamprosate Suppresses Ethanol-Induced Place Preference in Mice With Ethanol Physical Dependence
}

\author{
Kazuhiro Kurokawa ${ }^{1}$, Koji Mizuno $^{1}$, Masahiro Shibasaki ${ }^{1, \#}$, Masaya Higashioka ${ }^{2}$, Michiko Oka ${ }^{2}$, \\ Masaaki Hirouchi ${ }^{2}$, and Seitaro Ohkuma ${ }^{1, *}$ \\ ${ }^{1}$ Department of Pharmacology, Kawasaki Medical School, Matsushima 577, Kurashiki 701-0192, Japan \\ ${ }^{2}$ Research Laboratories, Nippon Shinyaku Co., Ltd., 14, Nishinosho-monguchi-cho, Kisshoin, Minami-Ku, Kyoto 601-8550, \\ Japan
}

Received March 19, 2013; Accepted June 6, 2013

\begin{abstract}
The present study investigated the effect of acamprosate on ethanol (EtOH)-induced place preference in mice with EtOH physical dependence. The expression of EtOH $(2 \mathrm{~g} / \mathrm{kg}$, intraperitoneally)-induced place preference in mice without $\mathrm{EtOH}$ treatment before the experiment was dose-dependently suppressed by acamprosate. The levels of protein kinase A (PKA) and phospho-cAMP response element binding protein (p-CREB) in the limbic forebrain after EtOHconditioning in naïve mice was unchanged. Furthermore, mice on the 4th day of withdrawal from continuous EtOH vapor inhalation for 9 days showed transient and significant enhancement of $\mathrm{EtOH}(1 \mathrm{~g} / \mathrm{kg}$, intraperitoneally)-induced place preference, which was significantly suppressed by acamprosate $(300 \mathrm{mg} / \mathrm{kg}$, oral administration; p.o., once a day) administered daily for 3 days after withdrawal from $\mathrm{EtOH}$ inhalation and during $\mathrm{EtOH}-$ conditioning. PKA and p-CREB proteins in the limbic forebrain of EtOH-conditioned mice on 4th day of withdrawal from continuous EtOH inhalation for 9 days significantly increased, which were completely abolished by acamprosate. These findings suggest that the signal transduction pathway via the PKA-p-CREB pathway in the limbic forebrain may be functionally related to the development of sensitization of EtOH-induced place preference and provide a possible molecular basis for the pharmacological effect of acamprosate to prevent or reduce the relapse of alcohol dependence.
\end{abstract}

Keywords: ethanol, acamprosate, alcohol dependence, phospho-cAMP response element binding protein ( $\mathrm{p}-\mathrm{CREB}$ ), conditioned place preference

\section{Introduction}

The mesolimbic dopaminergic system projects its neuronal fibers predominantly to the nucleus accumbens and prefrontal cortex from the ventral tegmental area. A number of studies have reported the pathophysiological roles of this neuronal system in mediating the reinforcing and rewarding effects of psychostimulants including cocaine and ethanol $(\mathrm{EtOH})(1,2) . \mathrm{EtOH}$ increases the

"Present address: Department of Toxicology, Hoshi University School of Pharmacy and Pharmaceutical Sciences, 2-4-41 Ebara, Shinagawaku, Tokyo 142-8501, Japan

*Corresponding author. sohkuma@bcc.kawasaki-m.ac.jp

Published online in J-STAGE on August 1, 2013

doi: $10.1254 /$ jphs.13056FP firing rate of dopamine neurons in the ventral tegmental area (3) and the extracellular dopamine levels in the nucleus accumbens $(4,5)$. Based on those observations, the mesolimbic dopaminergic system is supposed to play an important role in the development and expression of EtOH-induced place preference. In addition, our recent reports demonstrate that the conditioning for 8 days with $\mathrm{EtOH}$ (EtOH administration: 1 time / 2 days) induces significant place preference (6), and that mice on the 3 days after the withdrawal from continuous $\mathrm{EtOH}$ vapor inhalation for 9 days show enhanced EtOH-induced place preference (7).

Accumulating evidence suggests that changes of transcription factors, such as the cyclic-AMP response element binding protein (CREB), in the nucleus accum- 
bens participate in the mechanism of the development of dependence on drugs of abuse (8-10). In addition, $\mathrm{EtOH}$ alters the increases in phosphorylation of CREB (p-CREB) and p-CREB appears to modulate EtOH self-administration and EtOH-drinking $(11,12)$. These changes of p-CREB level and cAMP response element (CRE)-mediated gene expression occur in several brain regions in response to drugs of abuse (13). We demonstrated in the recent report that p-CREB and PKA were up-regulated in the lower midbrain including the ventral tegmental area of mice with EtOH physical dependence (14). However, little is known about the changes of p-CREB and PKA in the nucleus accumbens of mice on the development of EtOH-induced place preference.

Because of the structural similarity of acamprosate to $\gamma$-aminobutyric acid (GABA) and taurine, studies focused on clarifying the mechanisms of action for the effect of acamprosate on functional interaction with inhibitory receptors, especially $\mathrm{GABA}_{\mathrm{A}}$ receptors (15). On the other hand, current investigations suggest that a possible action site of acamprosate may be $N$-methyl-Daspartate (NMDA) receptors (16). Furthermore, several investigations have demonstrated that in the nucleus accumbens, acamprosate blocks glutamate increase during EtOH withdrawal (17) and elevates extracellular dopamine level; the latter action of acamprosate is mediated via activating glycine receptors (18). However, the precise molecular mechanism of action of acamprosate on $\mathrm{EtOH}$-induced place preference remains unclear.

The clinical efficacy of acamprosate has been evaluated in clinical trials $(19,20)$, whereas recent studies carried out in the United States and Australia suggest that acamprosate is not superior to placebo $(21-23)$. On the other hand, previous reports using experimental animals have demonstrated that intraperitoneal (i.p.) administration of acamprosate inhibits the development of EtOH-induced place preference in mice (24). In addition, acamprosate has been reported to reduce EtOH consumption in animal models $(25-27)$. Therefore, as the first goal of this study, we attempted to confirm whether oral administration of acamprosate at a dose almost equivalent to that used in the clinical field modifies EtOH-induced conditioned place preference, especially in mice treated with continuous EtOH vapor inhalation prior to measuring EtOH-induced conditioned place preference. The second goal is to examine whether PKA and p-CREB protein expression, which is facilitated by dopamine, increase in the limbic forebrain of mice with enhanced EtOHinduced place preference, because few data on the biochemical mechanism of action of acamprosate on EtOH-induced place preference in mice are available at present.

\section{Materials and Methods}

\section{Reagents and antibodies}

EtOH was obtained from Wako Pure Chemicals (Osaka). Acamprosate was was a kind gift from Merck Santé S.A.S. (Lyon, France). Protease-inhibitor cocktail was obtained from Roche Diagnostics (Indianapolis, IN, USA). Antibodies against CREB (rabbit polyclonal anti-CREB, \#9197), phosphor-CREB (Ser133) (rabbit polyclonal anti-p-CREB, \#4276), and PKARI- $\alpha$ (rabbit polyclonal anti-PKA, \#5675) were purchased from Cell Signaling Techonology, Inc. (Boston, MA, USA). Mouse anti- $\beta$-actin (sc-47778) was obtained from Santa Cruz Biotechnology (Santa Cruz, CA, USA). Horseradish peroxidase-conjugated goat anti-rabbit IgG and goat anti-mouse IgG were the products of Southern Biotechnology Associates, Inc. (Birmingham, AL, USA). EtOH was dissolved in saline when injected i.p. Acamprosate was dissolved in distillated water. The other agents used here were locally available and of analytical grade.

\section{Animals}

Male ddY mice (8-week-old: 33 - 37 g; Japan SLC, Inc., Hamamatsu) were housed in a room maintained at $22^{\circ} \mathrm{C} \pm 1{ }^{\circ} \mathrm{C}$, and $55 \%$ humidity with a 12 -h light/dark cycle (light on 8:00 A.M. to 8:00 P.M.) for 1 week prior to the experiments. Mice were group-housed 4 per cage. Food and water were available ad libitum.

The study was conducted in compliance with the Law for Humane Treatment and Management of Animals of Japan (Law No. 105, October 1, 1973, as revised on June 1, 2006).

\section{Procedure for $\mathrm{EtOH}$ vapor inhalation}

EtOH vapor inhalation in mice was carried out by the previous method $(14,28,29)$ with a minor modification. Mice were housed in the cage for $1-2$ weeks before the beginning of the EtOH vapor inhalation. Mice with initial body weight of $40 \mathrm{~g}$ were continuously exposed to EtOH vapor (concentrations of $11 \mathrm{mg} / \mathrm{L}$ ) or air in a chamber with free access to food and drinking water for 9 days. Mice received an i.p. loading dose of $2.0 \mathrm{~g} / \mathrm{kg}$ $\mathrm{EtOH}$ and pyrazole $(68 \mathrm{mg} / \mathrm{kg})$ at the beginning of EtOH vapor inhalation. During continuous inhalation of EtOH vapor, mice were injected i.p. with pyrazole $(68 \mathrm{mg} / \mathrm{kg})$, an inhibitor of alcohol dehydrogenase, daily at 10:00 A.M. to stabilize the blood EtOH level. The blood EtOH levels in mice were approximately $2.00 \mathrm{mg} / \mathrm{ml}$ during EtOH vapor inhalation (30). Animals exposed to air instead of EtOH vapor with concomitant administration of pyrazole were used as the control. Mice were removed from the chamber at the end of the EtOH exposure (10th day) and thereafter were not injected with pyrazole. 
Acamprosate $(3,30,300 \mathrm{mg} / \mathrm{kg})$ was orally administrated at 11:00 A.M. during the withdrawal (treated on the 10th, 11th, and 12th days of the experiment) from EtOH vapor exposure for 9 days.

\section{Place conditioning}

Place conditioning was examined using mice with 3 different EtOH treatment schedules as described below. 1) Mice were conditioned with $\mathrm{EtOH}$ for 8 days (4 sessions) and then administered a single dose of acamprosate $1 \mathrm{~h}$ before post-conditioning test (Fig. 1A). 2) Mice continuously inhaled EtOH vapor for 9 days, then housed without treatment with acamprosate for 3 days, and finally EtOH conditioning (4 days: 2 sessions) with daily acamprosate administration (Fig. 3A). 3) Mice continuously inhaled EtOH vapor for 9 days, then housed with daily treatment with acamprosate for 3 days, and finally received $\mathrm{EtOH}$ conditioning (4 days: 2 sessions) with daily acamprosate administration (Figs. 4A, 5A, and 6A).

The apparatus consisting of a shuttle box that was made of acrylic resin boards and divided into 2 equalsized compartments as previously reported $(6,7)$ was used for place conditioning studies. One compartment was black with a smooth floor and the other was white with a textured floor to create equally inviting compartments. The conditioning place preference schedule consisted of three phases (pre-conditioning test, conditioning, and post-conditioning test).

The pre-conditioning test: Before the preconditioning test, mice were placed on the border of both compartments and then the amount of time that each mouse spent in each compartment during the 900-s session was recorded automatically using an infrared beam sensor (BS-CPP-MS; BrainSienceIdea, Co., Ltd., Osaka). The compartment in which the mouse spent a longer time was defined as the preferred compartment and the other compartment was defined as the non-preferred one. Mice spending more than $600 \mathrm{~s}$ in one compartment were excluded from the experiment. The remaining mice were divided into 2 groups according to place preference, that is, 1 group consisted of mice preferring the black compartment and the other consisted of those preferring the white compartment. The baseline preference in each test group for the black and white compartments was approximately $50 \%$. With such biased assignment, mice were conditioned in their non-preferred compartment [drug (EtOH)-paired compartment].

Conditioning sessions: Conditioning sessions followed the preconditioning test. During this test, mice administered $\mathrm{EtOH}$ were conditioned in the non-preferred compartment [drug (EtOH)-paired compartment] and those administered saline were placed in the preferred compartment (saline-paired compartment). That is, the day after the preconditioning test, mice were placed in the drug (EtOH)-paired compartment for $30 \mathrm{~min}$ immediately after i.p. injection of $\mathrm{EtOH}$ or placed in the saline-paired compartment for $30 \mathrm{~min}$ immediately after i.p. injection of saline, and on an alternative day, mice were conditioned in the saline-paired compartment for $30 \mathrm{~min}$ with saline injection or in the drug $(\mathrm{EtOH})$ paired compartment for 30 min with EtOH treatment, respectively. The experiment of Fig. 1B showed that mice received for $4 \mathrm{EtOH}(2 \mathrm{mg} / \mathrm{kg})$-paired sessions and 4 saline-paired sessions, respectively. Such a cycle of conditioning was carried out for 8 days. On the other hand, in the experiments in Figs. 3: $\mathrm{B}-\mathrm{C}, 4$ : B - C, 5: $\mathrm{B}-\mathrm{C}$, and 6: $\mathrm{B}-\mathrm{C}$, mice received for $2 \mathrm{EtOH}$ $(1 \mathrm{mg} / \mathrm{kg})$-paired sessions and 2 saline-paired sessions, respectively. Such a cycle of conditioning was carried out for 4 days. Moreover, acamprosate at one dose $(3,30$, $300 \mathrm{mg} / \mathrm{kg}$ ) was orally administered everyday $1 \mathrm{~h}$ before i.p. treatment with $\mathrm{EtOH}(1 \mathrm{mg} / \mathrm{kg})$ or saline during EtOH conditioning and for 3 days after withdrawal from continuous EtOH inhalation.

Post-conditioning test: On the day after the final conditioning session, a post-conditioning test identical to the pre-conditioning test was carried out for $900 \mathrm{~s}$. The preference for the drug-paired place was expressed as the mean difference between the duration spent in it during the pre- and post-conditioning tests. For the experiment shown in Fig. 1B, acamprosate (3, 30, $300 \mathrm{mg} / \mathrm{kg}$, p.o.) was administered $1 \mathrm{~h}$ before the post-conditioning test.

The schedule of place preference conditioning and the time to administer acamprosate are presented in Figs. 1A, 3A, 4A, 5A, and 6A.

\section{Tissue dissection and preparation of samples for western blotting}

Immediately after the post-conditioning test, the limbic forebrain (including the nucleus accumbens and olfactory tubercle) was dissected from the decapitated animal on an ice-cold glass plate and homogenized with ice-cold lysis buffer ( $\mathrm{pH} 7.5$ ) containing $10 \mathrm{mM}$ Tris- $\mathrm{HCl}, 150 \mathrm{mM} \mathrm{NaCl}, 0.5 \mathrm{mM}$ EDTA, $10 \mathrm{mM} \mathrm{NaF}$, and $0.5 \%$ Triton $\mathrm{X}-100$ with a protease-inhibitor cocktail. The homogenate was centrifuged at $1,000 \times g$ for $10 \mathrm{~min}$ at $4^{\circ} \mathrm{C}$. The resultant pellet was resuspended and centrifuged again at $1,000 \times \mathrm{g}$ for $10 \mathrm{~min}$ at $4^{\circ} \mathrm{C}$. The pellets thus obtained were used as the nucleus fractions for measuring the immunoreactivity of CREB and p-CREB, and the resultant supernatant was further centrifuged at $100,000 \times \mathrm{g}$ for $60 \mathrm{~min}$ at $4^{\circ} \mathrm{C}$. The supernatants were used as the cytosol fractions for measuring the immunoreactivity of PKA. 


\section{Immunoblotting}

Protein concentration in the samples was assayed by the method of Lowry et al. (31). After electrophoresis (applied proteins for PKA, $15 \mu \mathrm{g} /$ lane; for CREB and p-CREB, $20 \mu \mathrm{g} /$ lane) using a 3\% - 8\% Tris-acetate gel (size, $8 \times 8 \mathrm{~cm}$; thickness, $1.0 \mathrm{~mm}$; Invitrogen, Carlsbad, CA, USA) at $150 \mathrm{~V}$ for $60 \mathrm{~min}$, proteins separated on the gel were transferred to a nitrocellulose filter with a wet-type transblotter $(90 \mathrm{~V}, 60 \mathrm{~min})$. For immunoblot detection of separated proteins, the membrane was incubated overnight at $4^{\circ} \mathrm{C}$ with primary antibodies against PKA (rabbit polyclonal anti-PKA, 1:1000), CREB (rabbit polyclonal anti-CREB, 1:1000), p-CREB (rabbit polyclonal anti-p-CREB, 1:1000), and $\beta$-actin (mouse monoclonal anti- $\beta$-actin; $1: 3000)$ diluted in phosphate-buffered saline (PBS) containing 3\% nonfat dried milk, further incubated for $2 \mathrm{~h}$ at room temperature with horseradish peroxidase-conjugated goat anti-rabbit $\mathrm{IgG}$ and goat anti-mouse IgG diluted 1:5000 in PBS containing 3\% nonfat dried milk, and finlly washed 6 times (each washing for $10 \mathrm{~min}$ ) with PBS containing $0.1 \%$ Tween 20 . The separated proteins were thereafter detected by chemiluminescence detection reagents (GE Healthcare UK, Ltd., Amersham Place, Little Chalfont, UK) and were scanned with Image Quant LAS 4000 mini (GE Healthcare UK).

\section{Statistical analyses}

Each of the data was represented as the mean \pm S.E.M. Statistical analysis was carried out using Prism 5 (GraphPad, Inc., San Diego, CA, USA). The data obtained from all experiments except for the protein levels of PKA and p-CREB in Fig. 2: A and B were analyzed with Tukey's multiple comparison test. The statistical differences between saline- and EtOH-conditioned groups in Fig. 2: A and B were analyzed with Student's $t$-test. Statistical analysis of the data on dose-dependency was evaluated with the test for linear trend. A level of probability of 0.05 or less was evaluated to be significant.

\section{Results}

Effect of acamprosate on expression of EtOH-induced place preference

In order to investigate the effect of acamprosate on the expression of EtOH-induced place preference, acamprosate was administrated $1 \mathrm{~h}$ before the postconditioning. EtOH (2 g/kg, i.p.) produced significant place preference $(P<0.001)$, which was suppressed by acamprosate in a dose-dependent manner $(P<0.05$, test for linear trend; $P<0.001$, Fig. 1B). However, acamprosate $(300 \mathrm{mg} / \mathrm{kg}$, p.o.) alone showed neither significant place preference nor place aversion in mice.
(A)

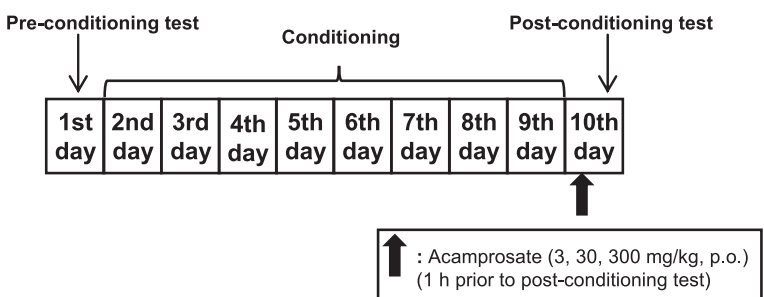

(B)

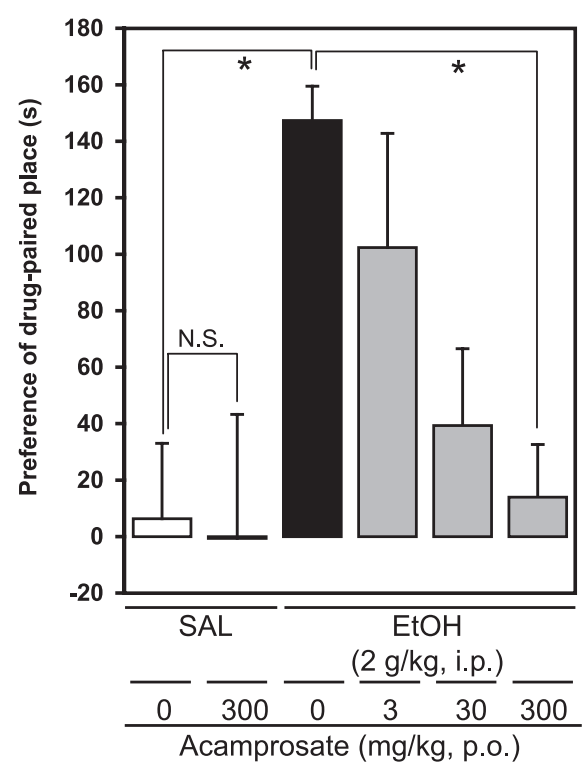

Fig. 1. Effect of acamprosate on expression of EtOH-induced place preference. A) Schedule of the experiment. B) Mice were conditioned by saline (SAL) and EtOH ( $2 \mathrm{mg} / \mathrm{kg}$, i.p.) every other day over the period for 8 days according to the conditioning schedule described in the text in detail. Post-conditioning test was performed $1 \mathrm{~h}$ after the treatment with acamprosate $(3,30$, and $300 \mathrm{mg} / \mathrm{kg}$, p.o.). Each column represents the mean \pm S.E.M. obtained from eight animals. N.S., not significant. $* P<0.05$ (Tukey's multiple comparison test).

Changes in protein levels of PKA and p-CREB in the limbic forebrain of mice during conditioned place preference to $\mathrm{EtOH}$

Using mice receiving the same experimental schedule presented in Fig. 1A, the changes in the protein levels of PKA and p-CREB in the limbic forebrain were examined by western blot analysis. PKA and p-CREB in the limbic forebrain showed no changes by EtOH conditioning (Fig. 2: B and C, respectively).

Effect of acamprosate on change of EtOH-induced place preference after continous EtOH vapor inhalation

In the first series of the experiments, acamprosate was administered only during EtOH-conditioning, but not treated with this drug during the 3 days after $\mathrm{EtOH}$ inhalation. Control mice (not treated with $\mathrm{EtOH}$ vapor for 9 days) conditioned by two-paired $\mathrm{EtOH}(1.0 \mathrm{~g} / \mathrm{kg})$ 
(A)

(B)
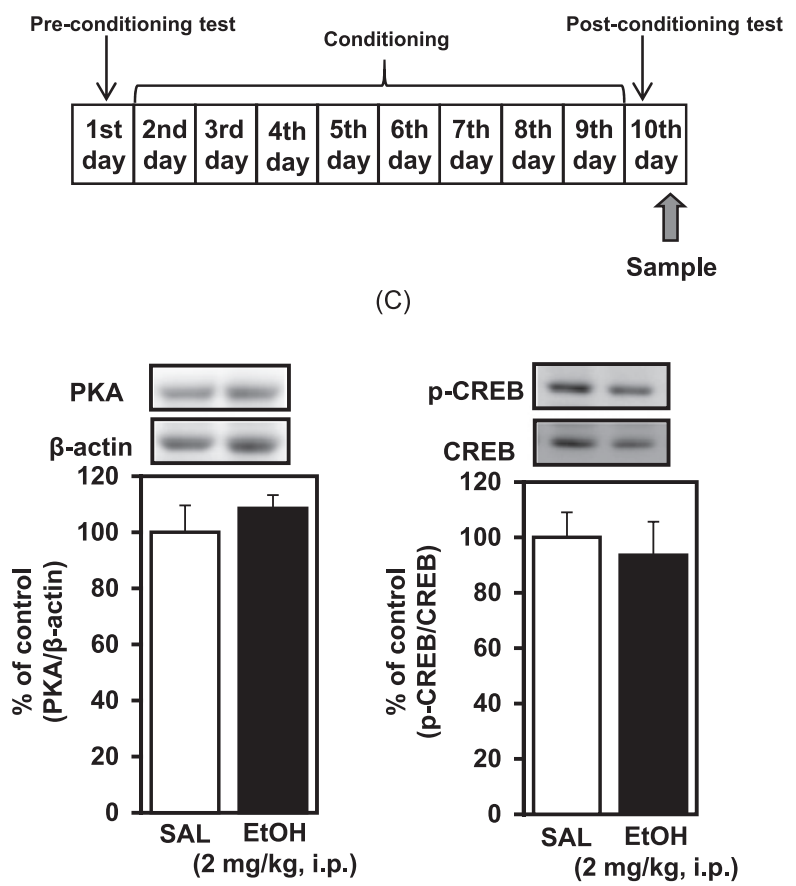

(C)

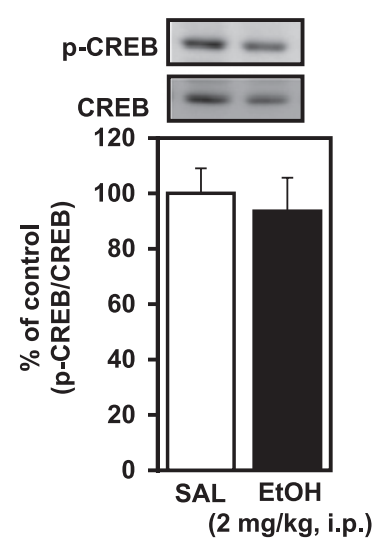

Fig. 2. Changes in protein levels of PKA and p-CREB in the limbic forebrain after EtOH-conditioning. A) Schedule of the experiment. B, C) Mice were conditioned by saline (SAL) and $\mathrm{EtOH}(2 \mathrm{mg} / \mathrm{kg}$, i.p.) every other day over the period for 8 days according to the conditioning schedule described in the text in detail. After the post-conditioning test, the cytosol and nucleus fractions used for measuring PKA (B) and p-CREB (C) expression were prepared $24 \mathrm{~h}$ after the last conditioning with EtOH or SAL. Each column represents the mean \pm S.E.M. of 5 mice.

sessions showed no significant place preference compared with saline conditioning mice (Fig. 3B). On the other hand, in mice after 3 days of the withdrawal from $\mathrm{EtOH}$ inhalation for 9 days, EtOH-conditioning with two-paired EtOH $(1.0 \mathrm{~g} / \mathrm{kg})$ sessions significantly increased place preference compared with salineconditioned mice $(P<0.001$, Fig. $3 C)$. Under such conditions, the increase in the EtOH-induced place preference was not significantly inhibited by acamprosate administered only during EtOH-conditioning (Fig. 3C).

In the second series of the experiments, acamprosate was administered during both 3 days after withdrawal from $\mathrm{EtOH}$ inhalation and $\mathrm{EtOH}-$ conditioning sessions. Increase in the EtOH-induced place preference $(P<0.001$, Fig. $4 C)$ was dose-dependently inhibited by acamprosate $(P<0.001$, test for linear trend; $P<0.001$, Fig. $4 \mathrm{C})$. However, acamprosate $(300 \mathrm{mg} / \mathrm{kg}$, p.o.) alone showed neither significant place preference nor place aversion in control mice. (Fig. 4: B and C).
Effect of acamprosate administered during 3 days of withdrawal from continuous EtOH inhalation for 9 days plus EtOH-conditioning on increase in PKA in the limbic forebrain of EtOH-conditioned mice

The protein levels of PKA in the limbic forebrain in control mice showed no changes by EtOH conditioning (Fig. 5B). On the other hand, in mice treated with continuous EtOH inhalation for 9 days, the expression of PKA significantly increased after EtOH conditioning $(P<0.05$, Fig. 5C). Such increased expression was completely abolished by the pretreatment with acamprosate during 3 days of withdrawal from continuous EtOH inhalation for 9 days plus EtOH-conditioning, at the dose that blocked the EtOH-induced place preference $(P<0.05$, Fig. 5C). Under such conditions, acamprosate had no effects on the expression of PKA proteins in saline-conditioning mice (Fig. 5: B and C).

Effect of acamprosate administered during 3 days of withdrawal from continuous EtOH inhalation for 9 days plus EtOH-conditioning on increase in p-CREB in the limbic forebrain of EtOH-conditioned mice

As shown in Fig. 6B, the protein level of p-CREB in the limbic forebrain in control mice showed no changes even after EtOH conditioning, whereas mice treated with continuous EtOH inhalation for 9 days significantly increased by EtOH conditioning $(P<0.01$, Fig. 6C). This increase was completely abolished by the pretreatment with acamprosate at the dose that blocked the EtOH-induced place preference $(P<0.01$, Fig. 6C). However, acamprosate had no effects on the expression of PKA proteins in saline-conditioning mice (Fig. 6: B and C).

\section{Discussion}

The present study demonstrates significant inhibitory effects of acamprosate orally administered on the expression of and the development of EtOH-induced place preference; the latter effect was observed in mice on the 3 days after withdrawal from continuous $\mathrm{EtOH}$ vapor inhalation.

Although the present study demonstrates the inhibitory potential of oral acamprosate on the expression of EtOHinduced place preference, previous reports have also demonstrated that the i.p. administration of acamprosate inhibits the development of EtOH-induced place preference in DBA mice (24). On the other hand, the protein levels of PKA and p-CREB in the limbic forebrain were unchanged in mice showing EtOH-induced place preference. Similarly, data have been reported that feeding of EtOH Liber-DeCarli liquid diet for 15 days caused no changes of PKA and p-CREB in the rat 


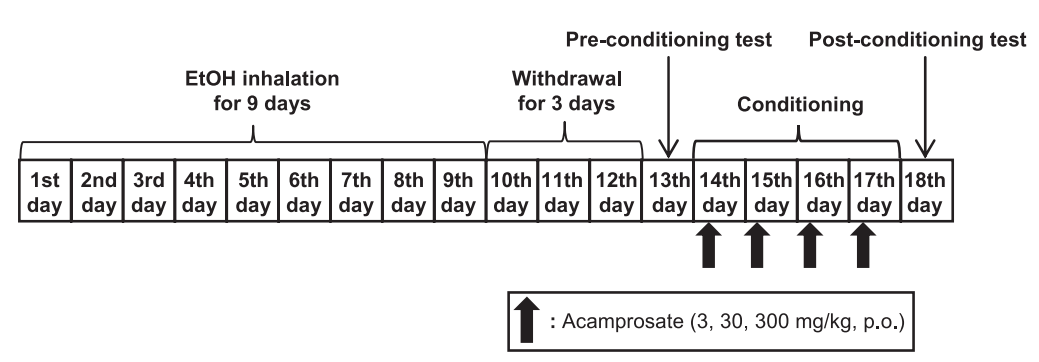

(B)

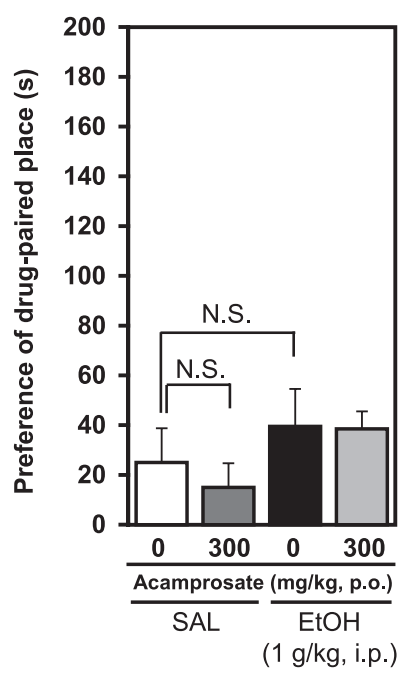

(C)

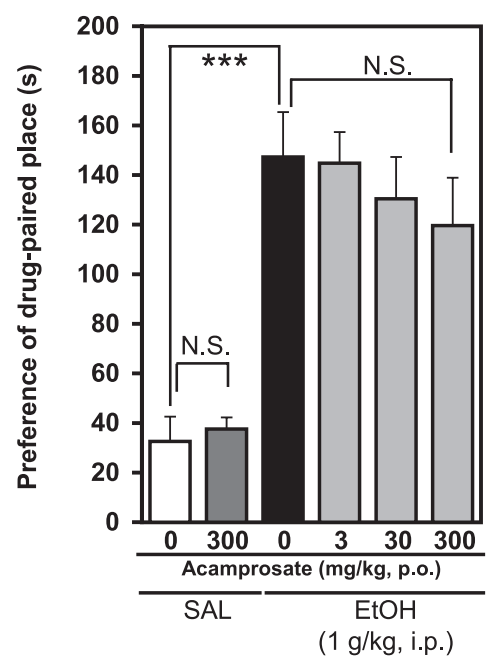

Fig. 3. Effect of acamprosate (administered during EtOH-conditioning for 4 days) on changes of EtOHinduced place preference after continuous EtOH vapor inhalation. A) Schedule of the experiment. B) Control mice were not treated with $\mathrm{EtOH}$ vapor inhalation. C) Mice were treated with continuous EtOH vapor inhalation for 9 days. In control mice and $\mathrm{EtOH}-$ inhaled (9 days) mice, oral acamprosate (3, 30, and $300 \mathrm{mg} / \mathrm{kg}$ ) administration was daily carried out $1 \mathrm{~h}$ before i.p. treatment with saline (SAL) and $\mathrm{EtOH}(1 \mathrm{~g} / \mathrm{kg})$ during EtOH-conditioning. For EtOH conditioning, mice were treated i.p. with SAL or EtOH two times every other day for 4 days (during the conditioning session: 2 days for EtOH, 2 days for SAL). Each column represents the mean \pm S.E.M. of 12 animals. N.S., not significant. $* * * P<0.001$ (Tukey's multiple comparison test). cortex (32). It is therefore considered to be reasonable that such short-term treatment with EtOH on conditioning may be inadequate to induce the increase of the expression of these proteins or that the time for measuring these proteins is too early to express the increase of these proteins in the brain.

Our recent study showed that mice after 3 days of withdrawal from continuous EtOH vapor inhalation for 9 days showed transient enhancement of EtOH $(1 \mathrm{~g} / \mathrm{kg})$ induced place preference (7), suggesting that the sensitization of EtOH-induced place preference as animal behaviors occurs in mice under these experimental conditions. Similarly, behavioral sensitization of locomotor activity to EtOH has been reported and this change of locomotor activity tends to be long-lasting (33). Furthermore, several reports have shown that the behavioral changes observed in animals after withdrawal from chronic EtOH exposure are considered to be due to adaptive changes in neurotransmission systems including glutamatergic and GABAergic transmission systems $(34,35)$. These experimental data suggest that the alternations of these neuronal transmission systems on and during withdrawal from EtOH physical dependence may develop sensitization to EtOH-induced place preference.

Recent studies suggest that acamprosate acts as an NMDA-receptor modulator $(16,36)$. Moreover, chronic $\mathrm{EtOH}$ treatment or withdrawal from it up-regulates NMDA-receptor function in the brain $(37-39)$, showing that NMDA receptors may play an important role in EtOH physical dependence and withdrawal from EtOH dependence. These data also suggest that the significant suppression of increase in EtOH-induced place preference by acamprosate after the withdrawal from continuous EtOH exposure may be mediated via the modulating action of acamprosate on NMDA-receptor function.

The interesting findings in present study are that acamprosate shows significant inhibitory potential to the increase of PKA and p-CREB in the limbic forebrain of mice after 3 days of the withdrawal from continuous $\mathrm{EtOH}$ vapor exposure as well as to increased EtOHconditioned place preference. A previous study suggests that activation of the PKA-regulated signaling pathway in the nucleus accumbens is one of potentially important mechanisms that may contribute to behavioral changes occurring across the addiction cycle (40). In addition, inhibition of PKA activity in the nucleus accumbens has 


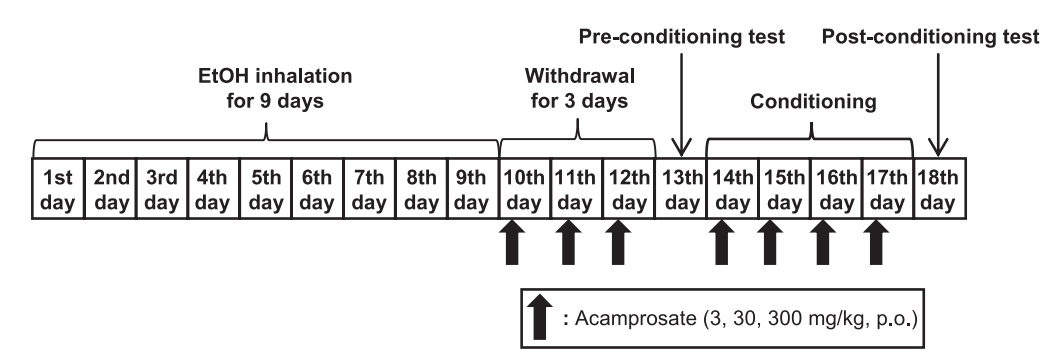

(B)

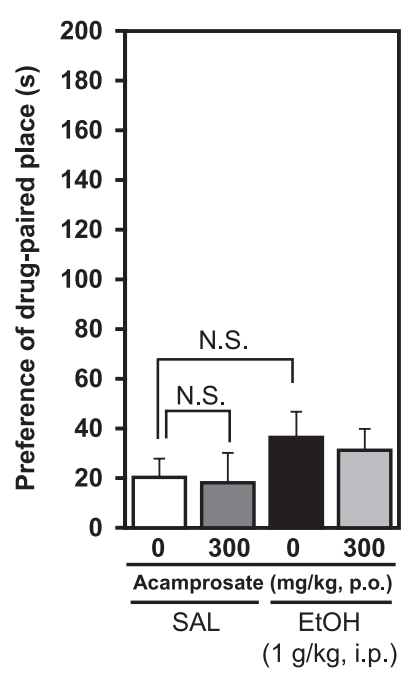

(A)

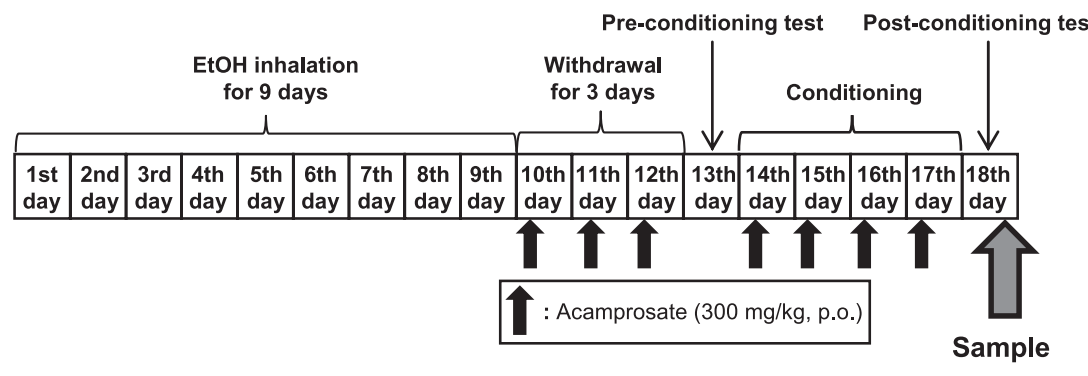

(B)

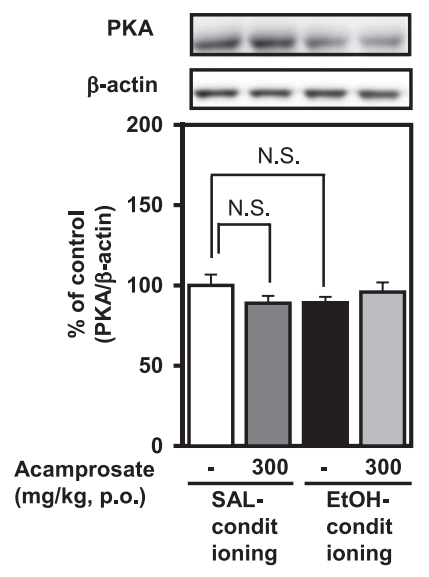

(C)

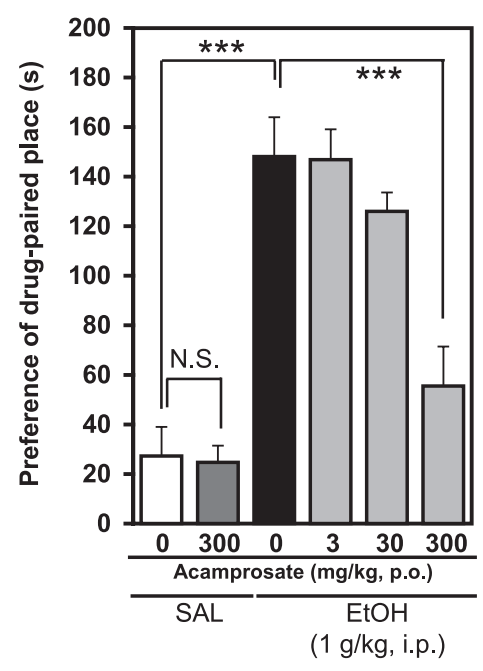

Fig. 4. Effect of acamprosate (administered during withdrawal from $\mathrm{EtOH}$ vapor for 3 days plus $\mathrm{EtOH}$ conditioning for 4 days) on changes of $\mathrm{EtOH}$-induced place preference after continuous EtOH vapor inhalation. A) Schedule of the experiment. B and C) control mice (B, not treated with EtOH vapor inhalation) and mice with continuous EtOH vapor inhalation for 9 days (C). Oral acamprosate (3, 30, and $300 \mathrm{mg} / \mathrm{kg}$ ) administration was carried out daily during withdrawal from EtOH vapor inhalation plus EtOH-conditioning. During the EtOH-conditioning period, acamprosate (3, 30 , and $300 \mathrm{mg} / \mathrm{kg}$ ) was orally administered $1 \mathrm{~h}$ before i.p. treatment with saline (SAL) and EtOH $(1 \mathrm{~g} / \mathrm{kg})$. For EtOH conditioning, mice were treated i.p. with SAL or EtOH two times every other day for 4 days (during the conditioning session: 2 days for $\mathrm{EtOH}$, 2 days for SAL) during conditioning period. Each column represents the mean \pm S.E.M. of $13-15$ animals. N.S., not significant. $* * * P<0.001$ (Tukey's multiple comparison test).

Fig. 5. Effect of acamprosate (administered during withdrawal from EtOH vapor for 3 days plus EtOH conditioning for 4 days) on enhanced expression of PKA in the limbic forebrain of mice after EtOH conditioning. A) Schedule of the experiment. B) Control mice were not treated with EtOH vapor inhalation. C) Mice inhaled EtOH vapor for 9 days. After mice inhaled EtOH vapor for 9 days, acamprosate $(300 \mathrm{mg} / \mathrm{kg})$ was orally administered daily for 3 days after the withdrawal from continuous EtOH inhalation and 4 days during EtOH conditioning. During the conditioning period, acamprosate (300 mg/kg) was orally administered $1 \mathrm{~h}$ before i.p. treatment with saline (SAL) and EtOH $(1 \mathrm{~g} / \mathrm{kg})$. For measuring $\mathrm{EtOH}$-induced place preference, mice were treated i.p. with SAL or EtOH two times every other day for 4 days (during the conditioning session: 2 days for $\mathrm{EtOH}, 2$ days for SAL) during the conditioning period. The cytosol fractions used for measuring PKA were prepared $24 \mathrm{~h}$ after the last conditioning with EtOH or saline. Each column represents the mean \pm S.E.M. of 4 mice. N.S., not significant. $* P<0.05$ (Tukey's multiple comparison test). 
(A)

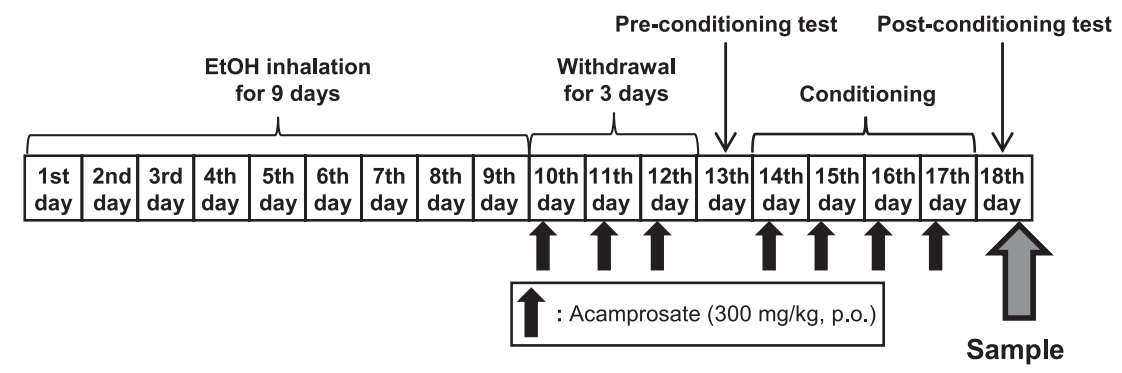

(B)

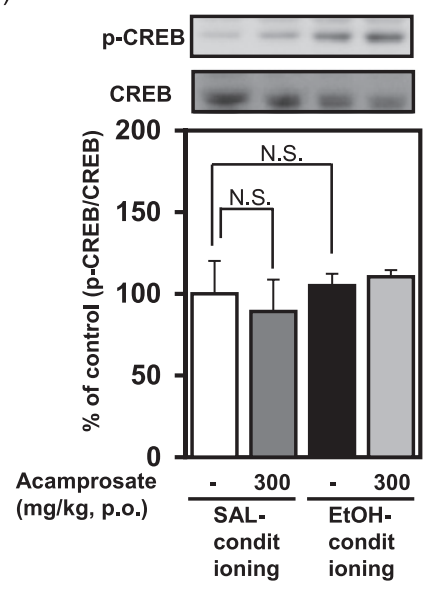

(C)

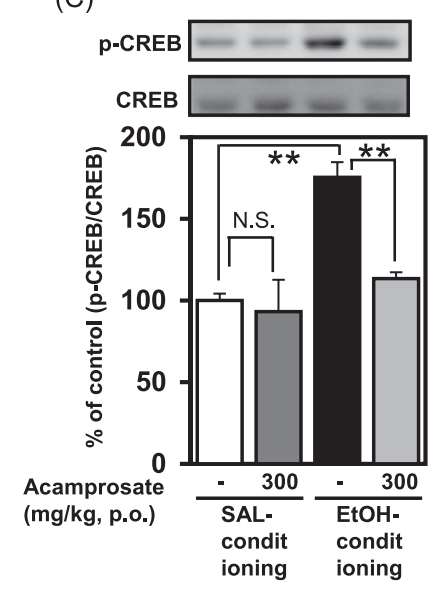

Fig. 6. Effect of acamprosate (administered during withdrawal from $\mathrm{EtOH}$ vapor for 3 days plus EtOH conditioning for 4 days) on enhanced expression of $\mathrm{p}$-CREB in the limbic forebrain of mice after EtOH conditioning. A) Schedule of the experiment. B) Control mice were not treated with $\mathrm{EtOH}$ vapor inhalation. C) Mice were continuously inhaled EtOH vapor for 9 days. After mice were inhaled EtOH vapor, acamprosate (300 $\mathrm{mg} / \mathrm{kg}$ ) was orally administered daily for 3 days after the withdrawal from continuous EtOH inhalation and 4 days during EtOH conditioning. During the conditioning period, acamprosate $(300 \mathrm{mg} / \mathrm{kg})$ was orally administered $1 \mathrm{~h}$ before i.p. treatment with saline (SAL) and EtOH $(1 \mathrm{~g} / \mathrm{kg})$. For measuring EtOH-induced place preference, mice were treated i.p. with SAL or EtOH two times every other day for 4 days (during the conditioning session: 2 days for $\mathrm{EtOH}, 2$ days for SAL) during the conditioning period. The nucleus fractions used for measuring p-CREB were prepared $24 \mathrm{~h}$ after the last conditioning with EtOH or saline. Each column represents the mean \pm S.E.M. of 4 mice. N.S., not significant. ${ }^{*} P<0.01$ (Tukey's multiple comparison test). been reported to attenuate amphetamine-induced place conditioning (41). These previous and present data suggest that the activation of PKA play an important role in EtOH-conditioned place preference.

Previous investigations demonstrated the up-regulation of NMDA receptors after EtOH exposure increased NMDA receptor-mediated calcium flux in cortical neurons $(37,42)$. Furthermore, activation of NMDA receptors increases CREB phosphorylation (43) and the number of p-CREB-immunoreactive cells in the shell of the nucleus accumbens in mice with behavioral sensitization after repeated treatment with to $\mathrm{EtOH}(44)$. The present study demonstrated that, in the limbic forebrain of EtOH-conditioned mice after 3 days of the withdrawal from continuous EtOH inhalation, increase of p-CREB protein expression was observed, which was abolished by the pretreatment with acamprosate. In addition, CREB can be also activated via phosphorylation by PKA. These results therefore suggest that the changes of p-CREB may be involved in the development of the sensitization of EtOH-induced place preference. However, exact mechanisms of regulatory effects of acamprosate on these neurochemical changes possibly involved in sensitization of EtOH-induced place preference remain to be elucidated.
In conclusion, the present study demonstrated that orally administered acamprosate inhibited the expression of EtOH-induced place preference. The increase in EtOH-induced place preference observed in mice after 3 days of withdrawal from EtOH physical dependence was inhibited by acamprosate. The increased expression of PKA and p-CREB in the limbic forebrain of EtOHconditioned mice 3 days after withdrawal from EtOH physical dependence were also inhibited by the acamprosate. These findings suggest that the signal transduction pathway mediated through the PKA-p-CREB pathway in the limbic forebrain may be functionally related to the development of sensitization of EtOH-induced place preference and provide a possible molecular basis for the pharmacological effect of acamprosate to prevent or reduce the relapse of alcohol dependence.

\section{Conflicts of Interest}

The author has no conflict of interest to disclose with respect to this study.

\section{References}

1 Nestler EJ. Is there a common molecular pathway for addiction? Nat Neurosci. 2005;8:1445-1449. 
2 Vanderschuren LJ, Kalivas PW. Alterations in dopaminergic and glutamatergic transmission in the induction and expression of behavioral sensitization: a critical review of preclinical studies. Psychopharmacology (Berl). 2000;151:99-120.

3 Foddai M, Dosia G, Spiga S, Diana M. Acetaldehyde increases dopaminergic neuronal activity in the VTA. Neuropsychopharmacology. 2004;29:530-536.

4 Ding ZM, Rodd ZA, Engleman EA, McBride WJ. Sensitization of ventral tegmental area dopamine neurons to the stimulating effects of ethanol. Alcohol Clin Exp Res. 2009;33:1571-1581.

5 Yoshimoto K, McBride WJ, Lumeng L, Li TK. Alcohol stimulates the release of dopamine and serotonin in the nucleus accumbens. Alcohol. 1992;9:17-22.

6 Shibasaki M, Kurokawa K, Mizuno K, Ohkuma S. Effect of aripiprazole on anxiety associated with ethanol physical dependence and on ethanol-induced place preference. J Pharmacol Sci. 2012;118:215-224.

7 Shibasaki M, Kurokawa K, Mizuno K, Suzuki T, Ohkuma S. Actin dynamics in development of behavioral sensitization after withdrawal from long-term ethanol administration to mice. Alcohol Clin Exp Res. 2012;36:1385-1396.

8 Pliakas AM, Carlson RR, Neve RL, Konradi C, Nestler EJ, Carlezon WA Jr. Altered responsiveness to cocaine and increased immobility in the forced swim test associated with elevated cAMP response element-binding protein expression in nucleus accumbens. J Neurosci. 2001;21:7397-7403.

9 Robison AJ, Nestler EJ. Transcriptional and epigenetic mechanisms of addiction. Nat Rev Neurosci. 2011;12:623-637.

10 Dong Y, Green T, Saal D, Marie H, Neve R, Nestler EJ, et al. CREB modulates excitability of nucleus accumbens neurons. Nat Neurosci. 2006;9:475-477.

11 Pandey SC, Roy A, Zhang H, Xu T. Partial deletion of the cAMP response element-binding protein gene promotes alcoholdrinking behaviors. J Neurosci. 2004;24:5022-5030.

12 Yang X, Horn K, Wand GS. Chronic ethanol exposure impairs phosphorylation of CREB and CRE-binding activity in rat striatum. Alcohol Clin Exp Res. 1998;22:382-390.

13 Nestler EJ. Molecular basis of long-term plasticity underlying addiction. Nat Rev Neurosci. 2001;2:119-128.

14 Shibasaki M, Mizuno K, Kurokawa K, Ohkuma S. Enhancement of histone acetylation in midbrain of mice with ethanol physical dependence and its withdrawal. Synapse. 2011;65:1244-1250.

15 Daoust M, Legrand E, Gewiss M, Heidbreder C, DeWitte P, Tran G, et al. Acamprosate modulates synaptosomal GABA transmission in chronically alcoholised rats. Pharmacol Biochem Behav. 1992;41:669-674.

16 Witkiewitz K, Saville K, Hamreus K. Acamprosate for treatment of alcohol dependence: mechanisms, efficacy, and clinical utility. Ther Clin Risk Manag. 2012;8:45-53.

17 Hinton DJ, Lee MR, Jacobson TL, Mishra PK, Frye MA, Mrazek DA, et al. Ethanol withdrawal-induced brain metabolites and the pharmacological effects of acamprosate in mice lacking ENT1. Neuropharmacology. 2012;62:2480-2488.

18 Chau P, Stomberg R, Fagerberg A, Soderpalm B, Ericson M. Glycine receptors involved in acamprosate's modulation of accumbal dopamine levels: an in vivo microdialysis study. Alcohol Clin Exp Res. 2010;34:32-38.

19 Rosner S, Hackl-Herrwerth A, Leucht S, Lehert P, Vecchi S, Soyka M. Acamprosate for alcohol dependence. Cochrane Database Syst Rev. 2010:CD004332.
20 Bouza C, Angeles M, Munoz A, Amate JM. Efficacy and safety of naltrexone and acamprosate in the treatment of alcohol dependence: a systematic review. Addiction. 2004;99:811-828.

21 Anton RF, O'Malley SS, Ciraulo DA, Cisler RA, Couper D, Donovan DM, et al. Combined pharmacotherapies and behavioral interventions for alcohol dependence: the COMBINE study: a randomized controlled trial. JAMA. 2006;295:20032017.

22 Morley KC, Teesson M, Reid SC, Sannibale C, Thomson C, Phung N, et al. Naltrexone versus acamprosate in the treatment of alcohol dependence: a multi-centre, randomized, doubleblind, placebo-controlled trial. Addiction. 2006;101:1451-1462.

23 Mason BJ, Goodman AM, Chabac S, Lehert P. Effect of oral acamprosate on abstinence in patients with alcohol dependence in a double-blind, placebo-controlled trial: the role of patient motivation. J Psychiatr Res. 2006;40:383-393.

$24 \mathrm{McGeehan}$ AJ, Olive MF. The anti-relapse compound acamprosate inhibits the development of a conditioned place preference to ethanol and cocaine but not morphine. Br J Pharmacol. 2003;138:9-12.

25 Gewiss M, Heidbreder C, Opsomer L, Durbin P, De Witte P. Acamprosate and diazepam differentially modulate alcoholinduced behavioural and cortical alterations in rats following chronic inhalation of ethanol vapour. Alcohol Alcohol. 1991;26:129-137.

26 Heyser CJ, Schulteis G, Durbin P, Koob GF. Chronic acamprosate eliminates the alcohol deprivation effect while having limited effects on baseline responding for ethanol in rats. Neuropsychopharmacology. 1998;18:125-133.

27 Lee MR, Hinton DJ, Wu J, Mishra PK, Port JD, Macura SI, et al. Acamprosate reduces ethanol drinking behaviors and alters the metabolite profile in mice lacking ENT1. Neurosci Lett. 2011;490:90-95.

28 Goldstein DB. Relationship of alcohol dose to intensity of withdrawal signs in mice. J Pharmacol Exp Ther. 1972;180: 203-215.

29 Shibasaki M, Inoue M, Kurokawa K, Ogou S, Ohkuma S. Expression of serotonin transporter in mice with ethanol physical dependency. J Pharmacol Sci. 2010;114:234-237.

30 Kurokawa K, Mizuno K, Ohkuma S. Dopamine D1 receptor signaling system regulates ryanodine receptor expression in ethanol physical dependence. Alcohol Clin Exp Res. 2013;37: 771-783.

31 Lowry OH, Rosebrough NJ, Farr AL, Randall RJ. Protein measurement with the Folin phenol reagent. J Biol Chem. 1951;193:265-275.

32 Pandey SC, Roy A, Mittal N. Effects of chronic ethanol intake and its withdrawal on the expression and phosphorylation of the creb gene transcription factor in rat cortex. J Pharmacol Exp Ther. 2001;296:857-868.

33 Lessov CN, Phillips TJ. Duration of sensitization to the locomotor stimulant effects of ethanol in mice. Psychopharmacology (Berl). 1998;135:374-382.

34 Lack AK, Diaz MR, Chappell A, DuBois DW, McCool BA. Chronic ethanol and withdrawal differentially modulate pre- and postsynaptic function at glutamatergic synapses in rat basolateral amygdala. J Neurophysiol. 2007;98:3185-3196.

35 Nestler EJ, Aghajanian GK. Molecular and cellular basis of addiction. Science. 1997;278:58-63.

36 Mason BJ, Heyser CJ. Acamprosate: a prototypic neuro- 
modulator in the treatment of alcohol dependence. CNS Neurol Disord Drug Targets. 2010;9:23-32.

37 Chandler LJ, Newsom H, Sumners C, Crews F. Chronic ethanol exposure potentiates NMDA excitotoxicity in cerebral cortical neurons. J Neurochem. 1993;60:1578-1581.

38 Hoffman PL, Tabakoff B. The role of the NMDA receptor in ethanol withdrawal. EXS. 1994;71:61-70.

39 Nagy J. Alcohol related changes in regulation of NMDA receptor functions. Curr Neuropharmacol. 2008;6:39-54.

40 Lynch WJ, Taylor JR. Persistent changes in motivation to selfadminister cocaine following modulation of cyclic AMPdependent protein kinase A (PKA) activity in the nucleus accumbens. Eur J Neurosci. 2005;22:1214-1220.

41 Beninger RJ, Nakonechny PL, Savina I. cAMP-dependent protein kinase and reward-related learning: intra-accumbens Rp-cAMPS blocks amphetamine-produced place conditioning in rats. Psychopharmacology (Berl). 2003;170:23-32.

42 Ahern KB, Lustig HS, Greenberg DA. Enhancement of NMDA toxicity and calcium responses by chronic exposure of cultured cortical neurons to ethanol. Neurosci Lett. 1994;165:211-214.

43 Ehlers MD. Activity level controls postsynaptic composition and signaling via the ubiquitin-proteasome system. Nat Neurosci. 2003;6:231-242.

44 Nona CN, Guirguis S, Nobrega JN. Susceptibility to ethanol sensitization is differentially associated with changes in pCREB, trkB and BDNF mRNA expression in the mouse brain. Behav Brain Res. 2013;242:25-33. 